\title{
A Cucumber AGAMOUS-LIKE 15 (AGL15) MADS-Box Gene Mediates Abnormal Leaf Morphology in Arabidopsis
}

\author{
Yong Zhou ${ }^{1,2,+(\mathbb{D}}$, Lingli Ge ${ }^{3,+}(\mathbb{D})$, Lifang $\mathrm{Hu}^{2,3} \mathbb{D}$, Yingui Yang ${ }^{3}(\mathbb{D})$ and Shiqiang Liu ${ }^{1, *(\mathbb{D})}$ \\ 1 College of Science, Jiangxi Agricultural University, Nanchang 330045, China; yzhoujxau@163.com \\ 2 Key Laboratory of Crop Physiology, Ecology and Genetic Breeding, Ministry of Education, \\ Jiangxi Agricultural University, Nanchang 330045, China; lfhu_hn337@163.com \\ 3 College of Agronomy, Jiangxi Agricultural University, Nanchang 330045, China; \\ gelingli0401@163.com (L.G.); yangyingui@163.com (Y.Y.) \\ * Correspondence: lsq_hn306@163.com; Tel.: +86-0791-83813574 \\ + These authors contributed equally to this work.
}

Received: 19 October 2018; Accepted: 13 November 2018; Published: 17 November 2018

\begin{abstract}
The AGL15 subfamily MADS-box proteins play vital roles in various developmental processes, such as floral transition, somatic embryogenesis, and leaf and fruit development. In this work, an AtAGL15 ortholog, CsMADS26, was cloned from cucumber (Cucumis sativus L.). The open reading frame (ORF) of CsMADS26 is $669 \mathrm{bp}$ in length, encoding a predicted protein of 222 amino acids. The CsMADS26 protein contains a highly conserved MADS-box domain and a variable $\mathrm{C}$ domain, as well as less conserved I and K domains. Phylogenetic relationship analysis revealed that CsMADS26 was clustered into the AGL15 clade of AGL15 subfamily. Expression analysis based on qRT-PCR showed that CSMADS26 is mainly expressed in reproductive organs including flowers and fruits. Transgenic Arabidopsis plants with ectopic expression of CsMADS26 exhibited curled rosette and cauline leaves, and the leaf size was much smaller than that of wild-type (WT) plants. These results provide clues for the functional characterization of CsMADS26 in the future.
\end{abstract}

Keywords: cucumber; MADS-box; AGAMOUS-LIKE 15 (AGL15); transgenic Arabidopsis; curled leaf; leaf size

\section{Introduction}

MADS intervening keratin-like and C-terminal (MIKC)-type MADS-box transcription factors (TFs) are a type of MADS-box proteins only present in plants, and are known for the four characteristic domains from $\mathrm{N}$ to $\mathrm{C}$ terminus: the highly conserved MADS domain (M); the poorly conserved intervening domain (I); the relatively conserved Keratin-like domain (K); and the most variable $\mathrm{C}$-terminal domain (C) [1,2]. According to the structural divergence of I and K domains, MIKC-type MADS-box genes are further classified into two subgroups named as MIKC ${ }^{C}$ and MIKC ${ }^{*}[3,4]$. The MIKC ${ }^{\mathrm{C}}$-type is the MADS-box that has been most extensively studied in plants, and can be further divided into at least 13 subfamilies named after their first identified members, such as AGAMOUS (AG), SHORT VEGETATIVE PHASE (SVP), FLOWERING LOCUS C (FLC), APETALA1 (AP1), AP3, SUPPRESSOR OF OVEREXPRESSION OF CO1 (SOC1), SEPALLATA (SEP), AGAMOUS-LIKE 6

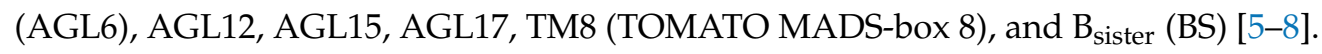

AGL15 and AGAMOUS-LIKE18 (AGL18) constitute the AGL15 subfamily, and many AGL15 subfamily members were recently identified by genome-wide approaches in many plant species, including Cucumis melo [6], Pyrus bretschneideri [9], Ziziphus jujuba [10], Gossypium hirsutum [2,11], Dianthus caryophyllus [12], Morus notabilis [7], and Hevea brasiliensis [13]. These studies showed 
that the expression of AGL15 subfamily members is primarily detected in floral organs, implying their important roles in the development of floral organs. For example, agl15 agl18 double mutants displayed an early flowering phenotype, which was not observed in agl15 or agl18 single mutants, suggesting that AtAGL15 and AtAGL18 act as co-repressors for floral transition [14]. Further studies showed that AtAGL15 can interact with AtAGL18 to form a complex with other proteins, which could directly bind to the promoters of $M I R 156 \mathrm{a} / \mathrm{c}$ to activate the expression of MIR156, and delay the floral transition in Arabidopsis [15]. In addition to controlling floral transition, ectopic expression of AtAGL15 or AtAGL18 in Arabidopsis can also enhance somatic embryogenesis, affect leaf morphogenesis, reduce fertility, and delay floral organ senescence and abscission [14,16,17], indicating the redundant functions of AtAGL15 and AtAGL18 in these developmental processes. AtAGL15 orthologs have been functionally characterized in other plants, such as cotton (G. hirsutum) [18], soybean (Glycine max) [19-21], Rosa canina [22], and Brassica juncea [23]. In addition, AGL15 members can control diverse developmental processes by modulating the hormone signaling pathways. For example, AtAGL15 and GmAGL15 negatively regulate auxin signaling pathway to promote somatic embryogenesis in Arabidopsis and soybean, and this regulation is integrated with GA metabolism and ethylene signaling pathway [19,20,24,25]. Overexpression of an AtAGL15 ortholog from R. canina in Arabidopsis altered floral organ morphology and numbers, as well as somatic embryogenesis, with a reduction in IAA and GA contents [22].

Recently, several MADS-box members have been identified and functionally characterized in cucumber [26,27]. However, the biological function of AtAGL15 orthologs in cucumber has not been elucidated. In this study, an AGL15 gene (CsMADS26) was isolated from cucumber based on the sequence of Csa020302 available in our previous study [28]. To study the biological function of CsMADS26, we overexpressed this gene in Arabidopsis and examined the phenotypes of the transgenic plants. The findings may aid in further clarification of the biological function of CsMADS26 in the growth and development of cucumber.

\section{Materials and Methods}

\subsection{Plants and Growth Conditions}

Cucumis sativus var. sativus line 9930 and Arabidopsis (Col-0) were used in this study. The cucumber seedlings were planted in the field of Jiangxi Agricultural University, Nanchang, China, under natural conditions. Wild-type (WT, Col-0) and transgenic Arabidopsis plants were planted in a growth room at $22{ }^{\circ} \mathrm{C}$ under long-day conditions ( $16 \mathrm{~h}$ of light/ $8 \mathrm{~h}$ of dark) with a relative humidity of $60 \%$.

\subsection{Isolation of the ORF of CsMADS26}

To isolate CSMADS26, flower RNA extraction was performed using the Trizol reagent (TianGen, Beijing, China) according to the manufacturer's protocol. The concentrations of RNA were examined by using Nanodrop 2000 (Thermo Fisher Scientific, Wilmington, NC, USA) and the RNA integrity was verified by agarose gel electrophoresis. After removal of potential DNA contamination, the first-strand cDNA was synthesized by using the TransScript One-Step gDNA Removal and cDNA Synthesis SuperMix kit (TransGen, Beijing, China) from $3 \mu \mathrm{g}$ of total RNA.

The specific primers (CsMADS26-1F: 5'-ATGGGTCGAGGGAAGATTGAAAT-3', and CsMADS26-1R: 5'-TTACCCCAAGTGCAAGGTGGTGT-3') used for CsMADS26 gene (locus ID: Csa020302) were designed for amplifying the open reading frame (ORF) of CsMADS26 using cucumber flower cDNA as the template. The reverse transcription polymerase chain reaction (RT-PCR) reaction procedure was as follows: $5 \mathrm{~min}$ initial denaturation at $95^{\circ} \mathrm{C}$, followed by 30 cycles at $95^{\circ} \mathrm{C}$ for $1 \mathrm{~min}, 58^{\circ} \mathrm{C}$ for $1 \mathrm{~min}, 72{ }^{\circ} \mathrm{C}$ for $1 \mathrm{~min}$, and a final extension at $72{ }^{\circ} \mathrm{C}$ for $7 \mathrm{~min}$. The amplified products were separated on $1.0 \%$ agarose gel and purified using a nucleic acid purification kit (Sangon, Shanghai, China). The resulting PCR products were ligated into the pMD18-T vector (TaKaRa, Dalian, China). The positive pMD18-CsMADS26 clones were confirmed by PCR with the above-mentioned 
primers (CsMADS26-1F and CsMADS26-1R), and then sequenced at Tsingke Biological Technology Company (Tsingke, Beijing, China).

\subsection{Bioinformatics Analysis}

The physicochemical and biochemical properties of CsMADS26 protein were analyzed using the programs of ExPASy ProtParam and SOPMA [29]. The prediction of subcellular localization for CsMADS26 protein was executed by WoLF PSORT (https:/ /www.genscript.com/tools/wolf-psort). The online SMART server (http:/ / smart.embl-heidelberg.de) was employed to analyze the conserved domains of CsMADS26 protein. Multiple alignments were carried out using Clustal Omega [30], by aligning the sequences of CsMADS26 and AGL15 subfamily proteins from different plants. Subsequently, a phylogenetic tree was created by the MEGA 5.0 software using the Neighbor-Joining (NJ) method with default settings, except that the bootstrap value was set at 1000 replicates.

\subsection{Expression Analysis of the CsMADS26 Gene}

To investigate the tissue expression profiles of CsMADS26, total RNA was prepared from six different tissues of $C$. sativus var. sativus line 9930, including male flower, female flower, root, stem, leaf, and fruit. The first-strand cDNA was synthesized as described above, and quantitative real-time PCR (qRT-PCR) was employed to determine the expression of CsMADS26 in these tissues by using CsAct3 ( $5^{\prime}$-GGCAGTGGTGGTGAACAT- $3^{\prime}$, and $5^{\prime}$-GATTCTGGTGATGGTGTGAGTC-3 ${ }^{\prime}$ ) as the internal control. The CsMADS26-specific primers were as follows: CsMADS26-2F (5'-GCACAAGGTTGAGCGAGAG-3') and CsMADS26-2R (5'-TGAAGCCTAAGCCAGTGAGAT-3'). The qRT-PCR was conducted in triplicate on LightCycler 480 Real-Time PCR System with the SYBR Green I Master Mix (Roche), and the conditions were as follows: $95^{\circ} \mathrm{C}$ for $30 \mathrm{~s}$, followed by 40 cycles at $95^{\circ} \mathrm{C}$ for $5 \mathrm{~s}, 60^{\circ} \mathrm{C}$ for $30 \mathrm{~s}$, and $72{ }^{\circ} \mathrm{C}$ for $15 \mathrm{~s}$. The relative expression levels were calculated according to the $2^{-\Delta \Delta \mathrm{Ct}}$ method [31].

\subsection{Vector Construction and Genetic Transformation}

The positive pMD18-CsMADS26 was digested with Pst I and Xba I, and ligated into the $\mathrm{pHB}$ vector to generate the 35S::35S::CsMADS26 construct, in which the ORF of CsMADS26 was under the control of a double $35 \mathrm{~S}$ promoter, and the hygromycin gene was used as a selectable marker. The 35S::35S::CsMADS26 construct was introduced into Agrobacterium tumefaciens strain GV3101, and then the strains were transformed into Arabidopsis Col-0 plants with the floral-dip method [32].

\subsection{Molecular Confirmation and Phenotypic Evaluation of Transgenic Plants}

Transgenic lines were grown on half-strength MS agar medium supplied with $50 \mathrm{mg} / \mathrm{L}$ hygromycin, and then the positive transgenic plants were confirmed by RT-PCR detection. For RT-PCR, RNA from the leaves of transgenic lines and WT plants was isolated using the Trizol reagent (TianGen, Beijing, China) with the CsMADS26-specific primers (CsMADS26-3F: 5'-TTGGGAAAGGATCTCAC TGG-3', and CsMADS26-3R: 5'-CAGAGTTGCAGGCCATATCA-3'). The AtTubulin4 gene was used as the reference gene, and the primers for the quantification were $5^{\prime}$-GCGAACAGTTCACAGCTATGTT CA- $3^{\prime}$ and $5^{\prime}$-GAGGGAGCCATTGACAACATCTT- $3^{\prime}$. Positive $\mathrm{T}_{3}$ homozygous seeds of at least two transgenic lines displaying $100 \%$ germination rate were selected for subsequent phenotypic evaluation.

\section{Results and Discussion}

\subsection{Cloning and Sequence Analysis of CsMADS26}

According to the locus ID of the CsMADS26 gene [28], we cloned its ORF by RT-PCR using specific primers from cucumber flowers. The amplification results showed that the ORF of CsMADS26 is $669 \mathrm{bp}$ in length, and encodes a predicted protein of 222 amino acids, with a theoretical molecular weight (MW) of $25.36 \mathrm{kDa}$ and a predicted isoelectric point of 5.57 (Figure 1). In addition, CsMADS26 has 36 negatively charged and 31 positively charged amino acids, with a putative grand average of 
hydropathy index (GRAVY) of -0.494 , suggesting that CsMADS26 is highly hydrophilic. The domain analysis showed that CsMADS26 holds the M, I, K, and C domains (Figure 1), which is a typical characteristic of MIKC-type MADS-box proteins [1]. WoLF PSORT server analysis showed that the CsMADS26 protein is located in the nucleus. These results indicate that CsMADS26 is a MIKC-type MADS-box transcription factor.

\begin{tabular}{|c|c|}
\hline & 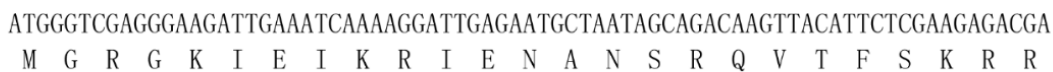 \\
\hline 6 & GCTGGGTTGCTTAAGAAGGCTCAAGAACTTGCTATTCTTTGTGATGCTGAAGTTGCTGTTATTATCTTCTCTAAT \\
\hline & $\begin{array}{llllllllllllllllllllllllll}A & G & \text { L } & \text { L } & \text { K } & \text { K } & \text { A } & \text { Q } & \text { E } & \text { L } & \text { A } & \text { I } & \text { L } & \text { C } & \text { D } & \text { A } & \text { E } & \text { V } & \text { A } & \text { V } & \text { I } & \text { I } & \text { F } & \text { S } & \text { N }\end{array}$ \\
\hline 51 & ACTGGCAAGCTTTTCGAGTTTTCTAGTTCTGGCATGAAGCACACTCTTGCAAGATACAACAAATGTGTAGAATCT \\
\hline & 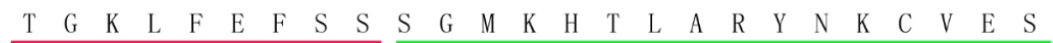 \\
\hline 26 & TCAGATGCTACAGTAGACGTGCACAAGGTTGAGCGAGAGCATGAGGAGGTAGACATTCTACGAGAGGAAATAACA \\
\hline & $\begin{array}{ccccccccccccccccccccccccc}S & D & A & T & V & D & V & H & K & V & E & R & E & H & E & E & V & D & I & L & R & E & E & I & T\end{array}$ \\
\hline 01 & ACTCTGCAAATGAAACAATTACAGCTATTGGGAAAGGATCTCACTGGCTTAGGCTTCAAAGAGTTGCAAAACCTG \\
\hline & 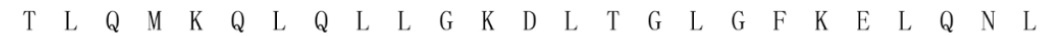 \\
\hline 76 & GAGCAACAGCTAAATGAAGGGCTATTACTGGTGAAAGAGAAGAAGGAACAGTTACTGATGGAGCAACTAGAGCAA \\
\hline & $\begin{array}{lllllllllllllllllllllllll}E & Q & Q & L & N & E & G & L & L & L & V & K & E & K & K & E & Q & L & L & M & E & Q & L & E & Q\end{array}$ \\
\hline 451 & TCAAGGGTACAGGAACAACGAGCAATGCTTGAGAACGAAACTCTGCGGAGACAGGTCAATGAGCTTCGGTGTCTG \\
\hline & $\begin{array}{lllllllllllllllllllllllll}S & R & V & Q & E & Q & R & A & M & L & E & N & E & T & L & R & R & Q & V & N & E & L & R & C & L\end{array}$ \\
\hline 526 & TTTCCGCCGGTTGATTGCCCCCTTCCAGCTTATCTTGAATACTGCTCCCTAGAGCAAAAGAATATTGGCATTAGA \\
\hline & $\begin{array}{ccccccccccccccccccccccccc}F & P & P & V & D & C & P & L & P & A & Y & L & E & Y & C & S & L & E & Q & K & N & I & G & I & R\end{array}$ \\
\hline & AGCCCTGATATGGCCTGCAACTCTGAAATTGAAAGAGGAGATTCAGACACCACCTTGCACTTGGGGTAA \\
\hline & 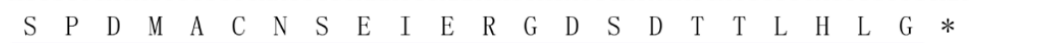 \\
\hline
\end{tabular}

Figure 1. Nucleotide and predicted amino acid sequences of CSMADS26. Stop codon is marked by asterisk. The M, I, K, and C domains are underlined with red, green, pink, and blue lines, respectively.

The secondary structure of the CsMADS26 protein was predicted by SOPMA. As a result, CsMADS26 contains $55.86 \%$ alpha helices, $12.61 \%$ extended strands, $4.50 \%$ beta turns, and $27.03 \%$ random coils, respectively (Figure 2). Previous reports have suggested that the K domain is mainly responsible for dimerization [2,9]. However, CsMADS26 possesses a large number of alpha helices in its $\mathrm{K}$ domain, suggesting that CsMADS26 may have a particular function in facilitating the dimerization of MADS-box proteins. Interestingly, the C domain of CsMADS26 mainly contains random coils (Figure 2), which might contribute to the formation of protein complex and transcriptional activation $[1,10]$.

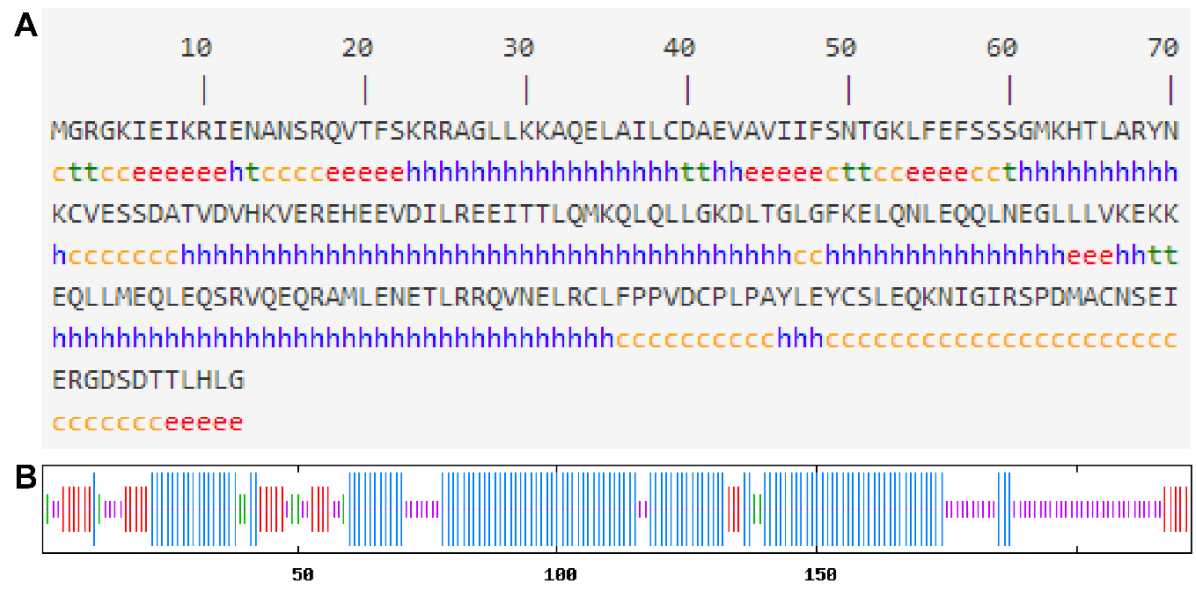

Figure 2. Secondary structure of CsMADS26 protein predicted by SOPMA. (A) Detailed amino acid information of CsMADS26 protein. The letters "c", "t", "e", and "h" represent random coil, beta turn, extended strand, and alpha helix, respectively. (B) Overview of the secondary structure of CsMADS26 protein. The blue longest lines, red lines, green lines, and purple shortest lines represent alpha helices, extended strands, beta turns, and random coils, respectively. 


\subsection{Sequence Alignment of CsMADS26 and Other AGL15 Subfamily Proteins}

The results of multiple sequence alignment revealed that CsMADS26 shares high amino acid identities with other AGL15 subfamily proteins. For example, it showed 78.28\%, 74.66\%, 73.30\%, 72.07\%, 70.32\%, 69.12\%, 62.16\%, and 60.95\% sequence identity with HbAGL15, ZjMADS45, PpMADS14, MnMADS6, VvMADS25, RcAGL15, SIMBP11, and AtAGL15, respectively (Figure 3). The alignment results also showed that all of these proteins contain a highly conserved $\mathrm{M}$ domain in the $\mathrm{N}$-terminus and a variable $\mathrm{C}$ domain in the $\mathrm{C}$-terminus, while the $\mathrm{I}$ and $\mathrm{K}$ domains are less conserved (Figure 3 ). Additionally, the signature motif of AGL15 subfamily proteins, SD(T/I)TL(Q/H)LGL, is present in the C-domain of these proteins, with the exception of CsMADS26, which lacks the last " $\mathrm{L}$ " residue. The signature motif is also present in some other AGL15 subfamily proteins $[18,23]$.

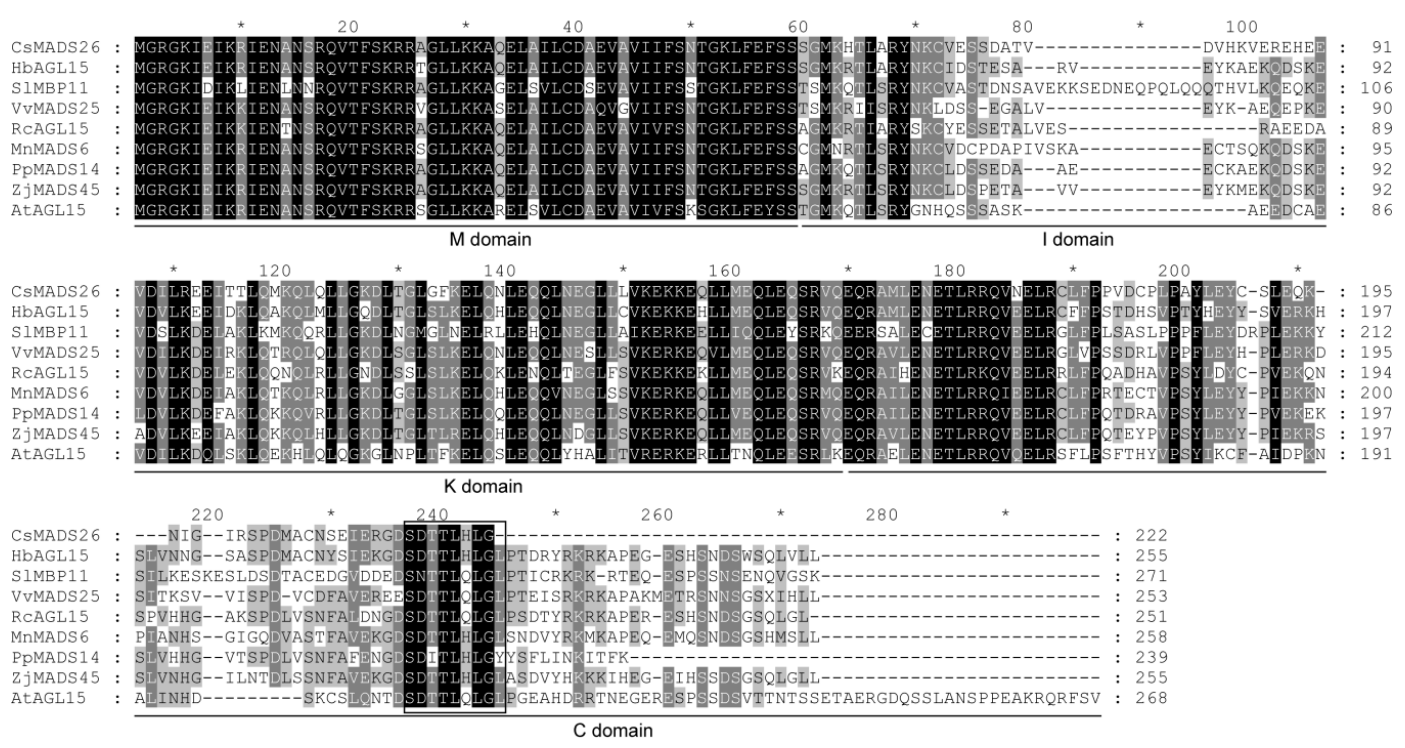

Figure 3. Sequence alignment of CsMADS26 and other AGL15 subfamily proteins. Multiple sequence alignment was performed by Clustal Omega using default settings with full-length amino acid sequences of these proteins. The M, I, K, and C domains are underlined. The signature sequences of AGL15 subfamily proteins are boxed. The AGL15 subfamily members used in the sequence alignment were obtained from Genbank, including AtAGL15 (Arabidopsis thaliana, At5g13790), RcAGL15 (Rosa canina, KM083102), SIMBP11 (Solanum lycopersicum, XM_004229626), PpMADS14 (Prunus persica, KU559580), VvMADS25 (Vitis vinifera, XM_003633492), ZjMADS45 (Ziziphus jujuba, XM_016026070.1), HbAGL15 (Hevea brasiliensis, KY471151), and MnMADS30 (Morus notabilis, EXC18224.1).

\subsection{Analysis of the Molecular Evolution of CsMADS26}

Our previous report has shown that CsMADS26 together with CsMADS25 belongs to the AGL15 subfamily of the MIKC ${ }^{C}$-type MADS-box proteins [28]. To dissect the phylogenetic relationships of CsMADS26 and AGL15 subfamily members from other plant species, a phylogenetic tree was created using NJ method with the amino acid sequences. The results demonstrated that these AGL15 subfamily proteins could be divided into two clades: AGL15 clade and AGL18 clade (Figure 4), indicating that AGL15 and AGL18 proteins might have evolved from one common ancestor in plants [27]. CsMADS26 together with CmMADS08 and other AGL15 proteins were clustered in the AGL15 clade, whereas CsMADS25 was grouped into the AGL18 clade (Figure 4). 


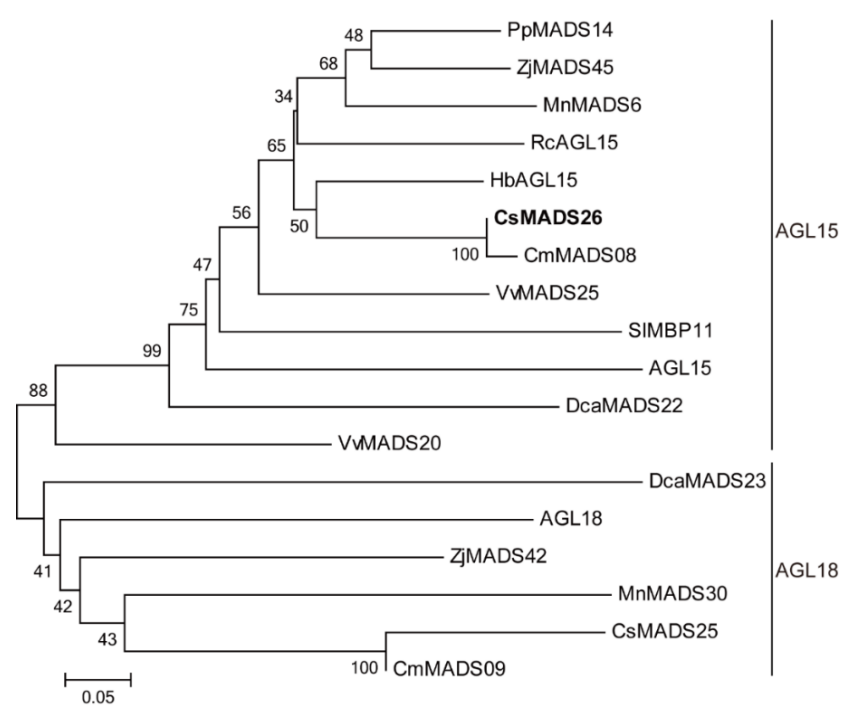

Figure 4. Phylogenetic relationships of CsMADS26 and AGL15 subfamily members from other plant species. Sequence alignment was carried out by using Clustal Omega with protein sequences from various plant species, and the alignment results were used to generate a NJ phylogenetic tree by MEGA 5.0 software with 1000 bootstrap replicates. The information and relative references of these proteins are provided in Table S1.

\subsection{Tissue Expression Profiles of CsMADS26 in Cucumber}

To evaluate the tissue expression profiles of CsMADS26 in cucumber, we performed qRT-PCR to analyze the transcript accumulation of CsMADS26 in different tissues, including male flower, female flower, root, stem, leaf, and fruit. As shown in Figure 5, the expression of CsMADS26 was detected in the six tested tissues, with the highest levels in male flower and female flower, followed by fruit and leaf, and much lower levels in stem and root. CSMADS26 is mainly expressed in reproductive organs, which is in agreement with the profiles of other AGL15 subfamily genes in various plants, including Prunus mume (PmMADS30) [33], Vitis vinifera (VvMADS20 and VvMADS25) [34], P. bretschneideri (PbrMADS34 and PbrMADS37) [9], Z. jujuba (ZjMADS42 and ZjMADS45) [10], G. hirsutum (GhAGL15-3) [2], D. caryophyllus (DcaMADS22 and DcaMADS23) [12], and M. notabilis (MnMADS6) [7], indicating its important function in the development of reproductive organs. In addition, its expression was also observed in leaf, indicating that CsMADS26 might play a role in leaf development.

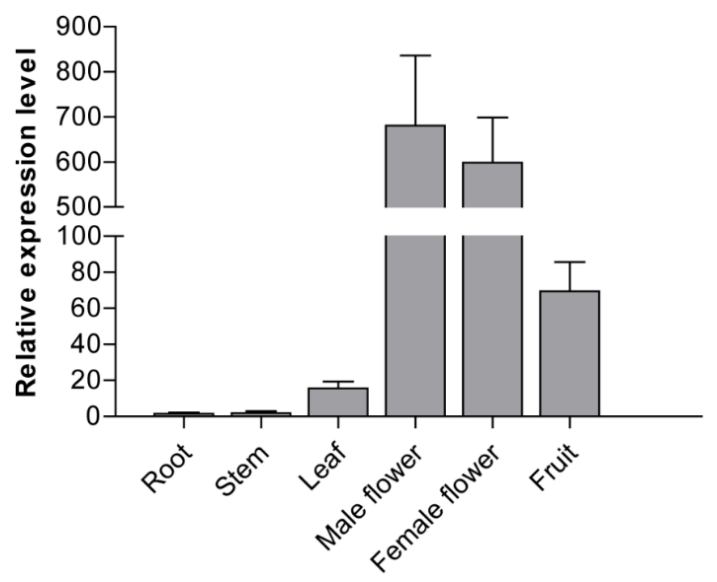

Figure 5. Expression profile analysis of CsMADS26 in various tissues of cucumber by qRT-PCR. The value for root was set as one when calculating the relative expression levels of CsMADS26 in other tissues. Data are presented as the mean values and standard deviation (SD) from three experimental replicates. 


\subsection{Abnormal Leaf Morphology Induced by CsMADS26 Overexpression in Arabidopsis}

To gain further insights into the function of CsMADS26, the ORF of CsMADS26 was inserted into $\mathrm{pHB}$ vector for ectopic expression in Arabidopsis (Figure 6A). All of the 14 independent positive 35S::35S::CsMADS26 transgenic plants displayed a phenotype of curled leaves, with 8 displaying a strong phenotype and 6 displaying a weak phenotype. In addition to curled leaves, no other phenotypes were observed in these positive transgenic plants. These transgenic lines were confirmed by RT-PCR analysis, and two lines (OE1 and OE2) were selected for further analysis (Figure 6B).
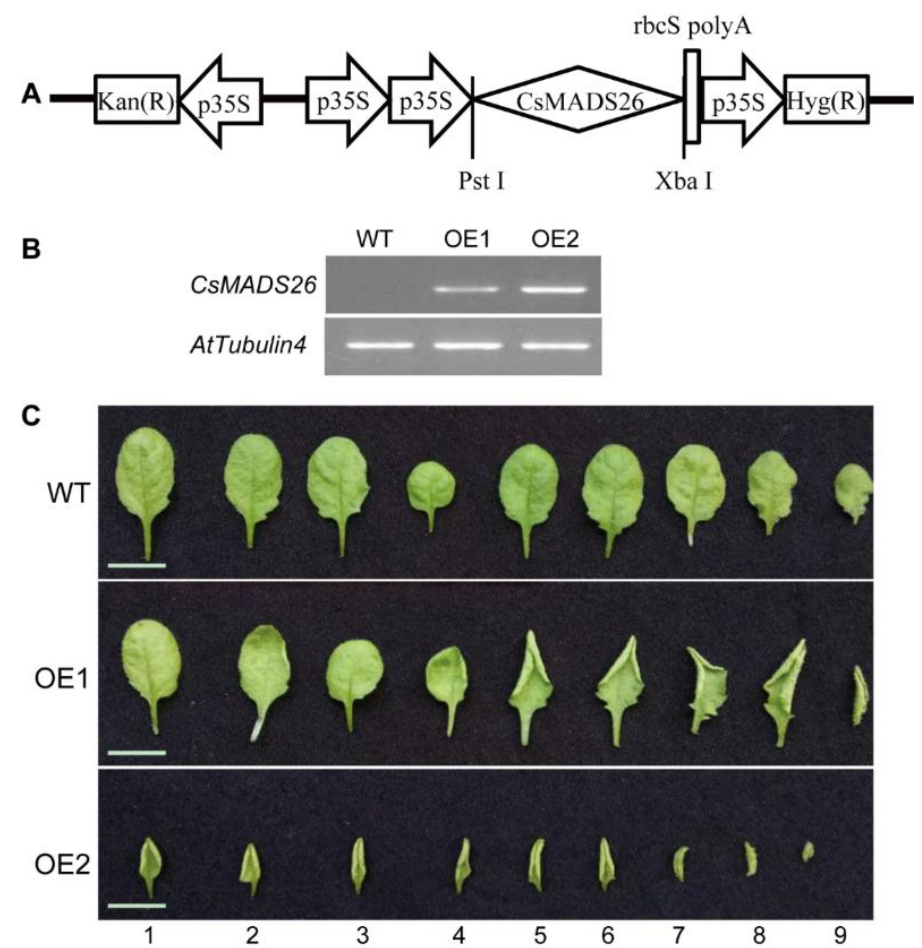

Figure 6. (A) Schematic diagram of 35S::35S::CsMADS26 construct used for Arabidopsis transformation. (B) RT-PCR analysis of the expression of CsMADS26 in WT and two transgenic lines (OE1 and OE2) by using the AtTubulin4 gene as an internal control. (C) Morphology of the rosette leaves in WT and transgenic plants (OE1 and OE2) under long-day conditions. The leaves were separated from 20-day-old plants. Bar $=1 \mathrm{~cm}$.

To further analyze the phenotype of curled leaves, we compared all the nine rosette leaves between WT and transgenic Arabidopsis plants. Compared with the WT plants, the 1st to 4th leaves of the transgenic line with low CSMADS26 expression (OE1) showed no significant phenotype of curled leaves, while the 5th to 9th leaves of OE1 exhibited an upward curling of the leaf margins (Figure 6C); in the transgenic line with high CSMADS26 expression (OE2), all of the leaves were severely curled, and the curling degree was much higher than that in OE1 and WT plants, suggesting that the curling of leaves may due to the overexpression of CsMADS26 in Arabidopsis. Similar to AtAGL15, the high expression of CsMADS26 in Arabidopsis may cause a decline in the expression of miR156 to regulate miR156-mediated target gene expression, including AtAGL15 and AtAGL18 [15]. agl15 agl18 agl24 svp mutations also resulted in upward curling of rosette and cauline leaves under long-day conditions, and the leaf curling is related to the expression of genes that are involved in floral organ development, such as SEP3 [16]. It is noteworthy that the number of rosette leaves and flowering time were not altered in transgenic plants, suggesting that CsMADS26 is not involved in regulating floral transition, which is different from the role of AtAGL15 [14]. In addition, the leaf size (length and width) of OE2 was much smaller than that of WT plants (Figure 6C). Similarly, overexpression of an AGL15 ortholog (SIMBP11) in tomato also caused decreases in the length and width of leaves [35]. Therefore, CsMADS26 may 
function in cucumber leaf development by interacting with its target genes expressed in leaves or through MADS protein dimerization.

\section{Conclusions}

In this study, we cloned the CSMADS26 gene from cucumber. Sequence and phylogenetic analysis showed that CsMADS26 is a MADS-box transcription factor and has a close relationship with AGL15 clade proteins of the AGL15 subfamily. CsMADS26 is mainly expressed in reproductive organs such as flowers and fruits. Ectopic expression of CSMADS26 could result in an abnormal leaf morphology including curled and small leaves in Arabidopsis. These results suggest the important role of CsMADS26 in regulating leaf development of cucumber.

Supplementary Materials: The following are available online at http://www.mdpi.com/2073-4395/8/11/ 265/s1. Table S1: The names and accession numbers of AGL15 subfamily proteins used for phylogenetic relationship analysis.

Author Contributions: data curation, Y.Z. and L.G.; funding acquisition, S.L.; methodology, L.G.; software, Y.Z. and L.H.; writing (original draft), Y.Z.; writing (review and editing), L.H., Y.Y. and S.L.

Funding: This research was funded by the Key Project of Youth Science Foundation of Jiangxi Province, grant number [20171ACB21025], and the National Natural Science Foundation of China, grant numbers [31460522 and 31660578].

Conflicts of Interest: The authors declare no conflict of interest.

\section{References}

1. Kaufmann, K.; Melzer, R.; Theissen, G. MIKC-type MADS-domain proteins: Structural modularity, protein interactions and network evolution in land plants. Gene 2005, 347, 183-198. [CrossRef] [PubMed]

2. Ren, Z.; Yu, D.; Yang, Z.; Li, C.; Qanmber, G.; Li, Y.; Li, J.; Liu, Z.; Lu, L.; Wang, L.; et al. Genome-wide identification of the MIKC-type MADS-box gene family in Gossypium hirsutum L. unravels their roles in flowering. Front. Plant Sci. 2017, 8, 384. [CrossRef] [PubMed]

3. Smaczniak, C.; Immink, R.G.; Angenent, G.C.; Kaufmann, K. Developmental and evolutionary diversity of plant MADS-domain factors: Insights from recent studies. Development 2012, 139, 3081-3098. [CrossRef] [PubMed]

4. Henschel, K.; Kofuji, R.; Hasebe, M.; Saedler, H.; Münster, T.; Theissen, G. Two ancient classes of MIKC-type MADS-box genesare present in the moss Physcomitrella patens. Mol. Biol. Evol. 2002, 19, 801-814. [CrossRef] [PubMed]

5. Li, H.F.; Dong, Q.L.; Li, G.X.; Ran, K. Identification and expression analysis of 11 MADS-box genes in peach (Prunus persica var. nectarina 'Luxing'). J. Hortic. Sci. Biotechnol. 2018, 93, 232-243. [CrossRef]

6. Hao, X.; Fu, Y.; Zhao, W.; Liu, L.; Bade, R.; Hasi, A.; Hao, J. Genome-wide identification and analysis of the MADS-box gene family in melon. J. Am. Soc. Hortic. Sci. 2016, 141, 507-519. [CrossRef]

7. Luo, Y.; Li, H.; Xiang, Z.; He, N. Identification of Morus notabilis MADS-box genes and elucidation of the roles of MnMADS33 during endodormancy. Sci. Rep. 2018, 8, 5860. [CrossRef] [PubMed]

8. Liu, J.; Zhang, J.; Zhang, J.; Miao, H.; Wang, J.; Gao, P.; Hu, W.; Jia, C.; Wang, Z.; Xu, B.; et al. Genome-wide analysis of banana MADS-box family closely related to fruit development and ripening. Sci. Rep. 2017, 7 , 3467. [CrossRef] [PubMed]

9. Wang, R.; Ming, M.; Li, J.; Shi, D.; Qiao, X.; Li, L.; Zhang, S.; Wu, J. Genome-wide identification of the MADS-box transcription factor family in pear (Pyrus bretschneideri) reveals evolution and functional divergence. PeerJ 2017, 5, e3776. [CrossRef] [PubMed]

10. Zhang, L.; Zhao, J.; Feng, C.; Liu, M.; Wang, J.; Hu, Y. Genome-wide identification, characterization of the MADS-box gene family in Chinese jujube and their involvement in flower development. Sci. Rep. 2017, 7, 1025. [CrossRef] [PubMed]

11. Nardeli, S.M.; Artico, S.; Aoyagi, G.M.; de Moura, S.M.; da Franca Silva, T.; Grossi-de-Sa, M.F.; Romanel, E.; Alves-Ferreira, M. Genome-wide analysis of the MADS-box gene family in polyploid cotton (Gossypium hirsutum) and in its diploid parental species (Gossypium arboreum and Gossypium raimondii). Plant Physiol. Biochem. 2018, 127, 169-184. [CrossRef] [PubMed] 
12. Zhang, X.; Wang, Q.; Yang, S.; Lin, S.; Bao, M.; Bendahmane, M.; Wu, Q.; Wang, C.; Fu, X. Identification and characterization of the MADS-box genes and their contribution to flower organ in carnation (Dianthus caryophyllus L.). Genes 2018, 9, 193. [CrossRef] [PubMed]

13. Wei, M.; Wang, Y.; Pan, R.; Li, W. Genome-wide identification and characterization of MADS-box family genes related to floral organ development and stress resistance in Hevea brasiliensis Müll. Arg. Forests 2018, 9, 304. [CrossRef]

14. Adamczyk, B.J.; Lehti-Shiu, M.D.; Fernandez, D.E. The MADS domain factors AGL15 and AGL18 act redundantly as repressors of the floral transition in Arabidopsis. Plant J. 2007, 50, 1007-1019. [CrossRef] [PubMed]

15. Serivichyaswat, P.; Ryu, H.S.; Kim, W.; Kim, S.; Chung, K.S.; Kim, J.J.; Ahn, J.H. Expression of the floral repressor miRNA156 is positively regulated by the AGAMOUS-like proteins AGL15 and AGL18. Mol. Cells 2015, 38, 259-266. [CrossRef] [PubMed]

16. Fernandez, D.E.; Wang, C.-T.; Zheng, Y.; Adamczyk, B.J.; Singhal, R.; Hall, P.K.; Perry, S.E. The MADS-domain factors AGAMOUS-LIKE15 and AGAMOUS-LIKE18, along with SHORT VEGETATIVE PHASE and AGAMOUS-LIKE24, are necessary to block floral gene expression during the vegetative phase. Plant Physiol. 2014, 165, 1591-1603. [CrossRef] [PubMed]

17. Fernandez, D.E.; Heck, G.R.; Perry, S.E.; Patterson, S.E.; Bleecker, A.B.; Fang, S.C. The embryo MADS domain factor AGL15 acts postembryonically: Inhibition of perianth senescence and abscission via constitutive expression. Plant Cell 2000, 12, 183-198. [CrossRef] [PubMed]

18. Yang, Z.; Li, C.; Wang, Y.; Zhang, C.; Wu, Z.; Zhang, X.; Liu, C.; Li, F. GhAGL15s, preferentially expressed during somatic embryogenesis, promote embryogenic callus formation in cotton (Gossypium hirsutum L.). Mol. Genet. Genomics 2014, 289, 873-883. [CrossRef] [PubMed]

19. Zheng, Q.; Zheng, Y.; Ji, H.; Burnie, W.; Perry, S.E. Gene regulation by the AGL15 transcription factor reveals hormone interactions in somatic embryogenesis. Plant Physiol. 2016, 172, 2374-2387. [CrossRef] [PubMed]

20. Zheng, Q.; Zheng, Y.; Perry, S.E. AGAMOUS-Like15 promotes somatic embryogenesis in Arabidopsis and soybean in part by the control of ethylene biosynthesis and response. Plant Physiol. 2013, 161, 2113-2127. [CrossRef] [PubMed]

21. Zheng, Q.; Perry, S.E. Alterations in the transcriptome of soybean in response to enhanced somatic embryogenesis promoted by orthologs of AGAMOUS-Like15 and AGAMOUS-Like18. Plant Physiol. 2014, 164, 1365-1377. [CrossRef] [PubMed]

22. Xu, K.; Liu, K.; Wu, J.; Wang, W.; Zhu, Y.; Li, C.; Zhao, M.; Wang, Y.; Li, C.; Zhao, L. A MADS-box gene associated with protocorm-like body formation in Rosa canina alters floral organ development in Arabidopsis. Can. J. Plant Sci. 2018, 98, 309-317. [CrossRef]

23. Li, C.; Ma, G.; Xie, T.; Chen, J.; Wang, Z.; Song, M.; Tang, Q. SOC1 and AGL24 interact with AGL18-1, not the other family members AGL18-2 and AGL18-3 in Brassica juncea. Acta Physiol. Plant. 2018, 40, 3. [CrossRef]

24. Wang, H.; Caruso, L.V.; Downie, A.B.; Perry, S.E. The embryo MADS domain protein AGAMOUS-Like 15 directly regulates expression of a gene encoding an enzyme involved in gibberellin metabolism. Plant Cell 2004, 16, 1206-1219. [CrossRef] [PubMed]

25. Zheng, Y.; Ren, N.; Wang, H.; Stromberg, A.J.; Perry, S.E. Global identification of targets of the Arabidopsis MADS domain protein AGAMOUS-Like15. Plant Cell 2009, 21, 2563-2577. [CrossRef] [PubMed]

26. Zhou, Y.; Hu, L.; Ge, L.; Li, G.; He, P.; Jiang, L.; Liu, S. Ectopic expression of CsMADS24, an AGAMOUS ortholog from cucumber, causes a homeotic conversion of sepals into carpels in transgenic Arabidopsis plants. Arch. Biol. Sci. 2018. [CrossRef]

27. Zhou, Y.; Hu, L.; Ge, L.; He, P.; Yang, Y.; Liu, S. Isolation and functional characterization of an AGAMOUS-LIKE 18 (AGL18) MADS-box gene from cucumber (Cucumis sativus L.). Not. Bot. Horti Agrobot. 2019. [CrossRef]

28. Hu, L.; Liu, S. Genome-wide analysis of the MADS-box gene family in cucumber. Genome 2012, 55, 245-256. [CrossRef] [PubMed]

29. Geourjon, C.; Deleage, G. SOPMA: Significant improvements in protein secondary structure prediction by consensus prediction from multiple alignments. Bioinformatics 1995, 11, 681-684. [CrossRef]

30. Sievers, F.; Wilm, A.; Dineen, D.; Gibson, T.J.; Karplus, K.; Li, W.; Lopez, R.; McWilliam, H.; Remmert, M.; Soding, J.; et al. Fast, scalable generation of high-quality protein multiple sequence alignments using Clustal Omega. Mol. Syst. Biol. 2011, 7, 539. [CrossRef] [PubMed] 
31. Livak, K.J.; Schmittgen, T.D. Analysis of relative gene expression data using real-time quantitative PCR and the $2^{-\Delta \Delta C t}$ method. Methods 2001, 25, 402-408. [CrossRef] [PubMed]

32. Clough, S.J.; Bent, A.F. Floral dip: A simplified method for Agrobacterium-mediated transformation of Arabidopsis thaliana. Plant J. 1998, 16, 735-743. [CrossRef] [PubMed]

33. Xu, Z.; Zhang, Q.; Sun, L.; Du, D.; Cheng, T.; Pan, H.; Yang, W.; Wang, J. Genome-wide identification, characterisation and expression analysis of the MADS-box gene family in Prunus mume. Mol. Genet. Genomics 2014, 289, 903-920. [CrossRef] [PubMed]

34. Wang, L.; Yin, X.; Cheng, C.; Wang, H.; Guo, R.; Xu, X.; Zhao, J.; Zheng, Y.; Wang, X. Evolutionary and expression analysis of a MADS-box gene superfamily involved in ovule development of seeded and seedless grapevines. Mol. Genet. Genomics 2015, 290, 825-846. [CrossRef] [PubMed]

35. Guo, X.; Chen, G.; Naeem, M.; Yu, X.; Tang, B.; Li, A.; Hu, Z. The MADS-box gene SlMBP11 regulates plant architecture and affects reproductive development in tomato plants. Plant Sci. 2017, 258, 90-101. [CrossRef] [PubMed]

(C) 2018 by the authors. Licensee MDPI, Basel, Switzerland. This article is an open access article distributed under the terms and conditions of the Creative Commons Attribution (CC BY) license (http:/ / creativecommons.org/licenses/by/4.0/). 